\title{
Enhanced Gene Transfer into HuH-7 Cells and Primary Rat Hepatocytes Using Targeted Liposomes and Polyethylenimine
}

BioTechniques 25:282-292 (August 1998)

\author{
Paramita Bandyopadhyay, \\ Betsy T. Kren, Xiaoming Ma \\ and Clifford J. Steer \\ University of Minnesota Med- \\ ical School, Minneapolis, MN, \\ USA
}

\begin{abstract}
Different ratios of DNA phosphate to polyethylenimine amine were used for encapsulation and delivery to liver cells of chloramphenicol acetyl transferase (CAT) or luciferase expression plasmids in cationic, neutral and anionic liposomes. Positive liposomes consisted of dioleoyl phosphatidylcholine (DOPC): dioleoyl trimethylammonium propane (DOTAP) (6:1 molar ratio); neutral liposomes were composed of DOPC and dioleoyl phosphatidylethanolamine (DOPE) (1:1); and negative liposomes contained dioleoyl phosphatidylserine (DOPS) and DOPC (1:1). All formulations included $8 \mathrm{~mol} \%$ galactocerebroside for targeting to the hepatocyte asialoglycoprotein receptor. Liposomes were prepared by film hydration followed by sequential extrusion through 0.8-0.2- $\mu \mathrm{m}$ polycarbonate membranes. Transfection efficiency of $\mathrm{HuH}-7$ human hepatoma cells and isolated rat hepatocytes was determined by CAT enzymelinked immunosorbent assay (ELISA) or luciferase activity. Uptake of liposomal-encapsulated, fluorescently labeled 68-mer oligonucleotides was assessed by confocal microscopy. All three formulations demonstrated a twofold or greater increase in transfection efficiency and significantly lower toxicity compared to nonencapsulated polyethylenimine complexes. Negative liposomes were most effective, particularly in the rat hepatocytes. Only the cationic and
\end{abstract}

anionic liposomal formulations exhibited significant thermodynamic stability. These formulations are readily characterized for size, phospholipid and DNA content, and they represent feasible systems for optimizing in vivo delivery systems to hepatocytes.

\section{INTRODUCTION}

The full potential of gene therapy has not yet been achieved due to the lack of optimized delivery systems and improved transfection efficiencies both in vitro and in vivo. Approaches to gene delivery include the use of adenoviral and retroviral vectors or a combination of the two systems and nonviral vectors such as cationic lipid complexes, polycation complexes and liposomes or a combination of one or more of the above $(7-9,17,19)$. There are three major barriers in the delivery of genetic material to cells: (i) stability of the DNA/RNA in the extracellular environment, (ii) transfer of genetic material across the cell membrane and (iii) delivery of the genetic material to the nucleus without intracellular degradation. While adenoviral and retroviral vectors have successfully been used for gene delivery both in vitro and in vivo, they are limited in their clinical use because of their potential for promoting genomic rearrangements and immunogenicity (23). Cationic lipid complexes can mediate gene transfer, but the toxicity of various cationic lipids also limits their in vivo use $(11,14)$. Polycation complexes of oligonucleotides or plasmids provide an alternative approach; however, they may still be associated with toxicity (e.g., complement activation), variable transfection efficiency, poor characterization and limited stability $(18,26)$.
Efforts to encapsulate nucleic acids in liposomes have been relatively imprecise, relying mainly on the electrostatic interaction between cationic lipids and the anionic nucleic acids $(6,20)$. In this paper, we describe the preparation and characterization of three different liposomal systems for the encapsulation of plasmid DNA and oligonucleotides: positive (cationic), negative (anionic) and neutral. These formulations were evaluated for their encapsulation efficiency, physical stability with prolonged storage and cytotoxicity. A branched-chain polycation, polyethyleneimine (PEI) was included in some of the formulations to further compact the nucleic acids before encapsulation (2). In vitro transfection efficiency was evaluated in actively replicating HuH-7 human hepatoma cells and in quiescent nondividing primary rat hepatocytes.

\section{MATERIALS AND METHODS}

\section{Plasmids and Oligonucleotides}

Plasmids encoding for the chloramphenicol acetyl transferase (CAT) enzyme, pRSV-CAT (Stratagene, La Jolla, CA, USA), or for the firefly luciferase gene, pGL3-Control Vector (Promega, Madison, WI, USA), were transformed into E. coli DH5 $\alpha$. Plasmid DNA was isolated from overnight cultures of DH5 $\alpha$ and purified by affinity chromatography on QIAGEN ${ }^{\circledR}$ columns (Qiagen, Chatsworth, CA, USA) according to manufacturer's protocol. The quality of the DNA was determined by UV spectroscopy and agarose gel electrophoresis $(0.8 \%-1 \%$ agarose) with 0.5 $\mu \mathrm{g} / \mathrm{mL}$ ethidium bromide. Plasmid 
Table 1. Size Analyses of Liposomal Formulations Containing Encapsulated Plasmid-PEI Complexes

\begin{tabular}{|c|c|c|c|}
\hline \multirow[b]{2}{*}{ Formulation (Composition) } & \multicolumn{3}{|c|}{ Size Distribution (Number Weighted Mean Diameter) } \\
\hline & Post-Extrusion & $\begin{array}{l}\text { Post-Storage } \\
\left.\text { (30 days, } 4^{\circ} \mathrm{C}\right)\end{array}$ & $\begin{array}{l}\text { Post-Incubation } \\
\left(18 \mathrm{~h}, 37^{\circ} \mathrm{C}\right)\end{array}$ \\
\hline $\begin{array}{l}\text { Cationic liposomes } \\
\text { (DOPC:DOTAP:Gc) } \\
6: 1: 0.56\end{array}$ & $115.6 \pm 46.7 \mathrm{~nm}$ & $137.1 \pm 37.7 \mathrm{~nm}$ & $91.2 \pm 41.1 \mathrm{~nm}$ \\
\hline $\begin{array}{l}\text { Neutral liposomes } \\
\text { (DOPC:DOPE:Gc) } \\
1: 1: 0.16\end{array}$ & $\begin{array}{c}265.7 \pm 467 \mathrm{~nm} \\
\text { (bimodal distribution) }\end{array}$ & $\begin{array}{c}\text { ca. } 1 \mu \mathrm{m} \\
\text { (heterogeneous) }\end{array}$ & $\begin{array}{c}\text { ca. } 1 \mu \mathrm{m} \\
\text { (heterogeneous) }\end{array}$ \\
\hline $\begin{array}{l}\text { Anionic liposomes } \\
\text { (DOPC:DOPS:Gc) } \\
1: 1: 0.16\end{array}$ & $118.2 \pm 40.8 \mathrm{~nm}$ & $106.1 \pm 39.6 \mathrm{~nm}$ & $135.7 \pm 39.2 \mathrm{~nm}$ \\
\hline
\end{tabular}

DNA was labeled with ethidium monoazide bromide (Molecular Probes, Eugene, OR, USA) as previously described (25). Following labeling, the non-covalently-bound ethidium products were removed by six butanol extractions (1), and the DNA was precipitated with ethanol. A 68-mer oligonucleotide was obtained from Genosys Biotechnologies, (The Woodlands, TX, USA) and was 3'-end-labeled using terminal transferase and fluorescein-12-dUTP from Boehringer Mannheim (Indianapolis, IN, USA) according to the manufacturer's recommendation. Labeled oligonucleotides were mixed with unlabeled oligonucleotides at a 2:3 ratio.

\section{Preparation of PEI-DNA Complexes}

PEI (800 kDa) was purchased from Fluka Chemical (Ronkonkoma, NY, USA). A PEI stock solution of $0.05 \mathrm{M}$ (monomer) in Milli-Q ${ }^{\circledR}$ water (Millipore, Bedford, MA, USA) was freshly prepared and its $\mathrm{pH}$ adjusted to 7.6 with $6 \mathrm{M} \mathrm{HCl}$. This PEI stock solution corresponded to approximately $50 \mathrm{nmol}$ amine $/ \mu \mathrm{L}$ (2). Plasmid DNA (100-250 $\mu \mathrm{g})$ and PEI (1 nmol DNA phosphate per 4-9 nmol amine) were each diluted into $250 \mu \mathrm{L} 0.15 \mathrm{M} \mathrm{NaCl}$. The solutions were vortex mixed separately for 5-10 min at room temperature (RT) followed by the dropwise addition of the PEI solution to the DNA. The combined material was vortex mixed for another 5-10 min before addition to the dried lipid film. A 1:2 complex (1 nmol DNA phosphate/2 nmol amine) was used for encapsulation of plasmids into the negatively charged liposomes. In fact, the decreased ratio of amine to DNA phosphate resulted in less aggregation between the excess PEI and dioleoyl phosphatidylserine (DOPS). This complex was not vortex mixed after PEI addition to the DNA but mixed by inversion and tapping.

\section{Liposome Formulations}

Dioleoyl phosphatidylcholine (DOPC), dioleoyl phosphatidylethanolamine (DOPE), DOPS, galactocerebroside (Gc) and dioleoyl trimethyl- ammoniumpropane (DOTAP) were purchased from Avanti Polar Lipids (Alabaster, AL, USA) as dried powders and used without further purification. Several 2-mg/mL stock solutions of the lipids were prepared in chloroform or chloroform:methanol (1:1 vol/vol) and stored in glass vials with Teflon ${ }^{\circledR}$-lined caps in dessicated containers at $-20^{\circ} \mathrm{C}$. Lipids were aliquoted in borosilicate tubes and dried under a stream of nitrogen just before use. Each formulation consisted of $500 \mu \mathrm{g}$ lipid.

Positively charged liposomes of DOPC:DOTAP:Gc were combined at a 6:1:0.56 molar ratio, and the lipid solution dried under nitrogen. DNA-PEI or oligonucleotide-PEI (1:4 or 1:9) complexes in $500 \mu \mathrm{L} 0.15 \mathrm{M} \mathrm{NaCl}$ were added to the film at RT and hydrated by alternate mild vortex mixing and warming at $37^{\circ} \mathrm{C}$ until all the lipid dispersed. The suspension was transferred to a Liposofast ${ }^{\mathrm{TM}}$ Mini-Extruder (Avestin, Ottawa, ON, Canada) and extruded through a series of decreasing polycarbonate membranes to a final pore size of $0.2 \mu \mathrm{m}$.
Negatively charged liposomes of DOPS:DOPC:Gc were combined at a 1:1:0.16 molar ratio and the solution dried under nitrogen. The plasmid-PEI (1:2) complex in $500 \mu \mathrm{L}$ of $0.15 \mathrm{M}$ $\mathrm{NaCl}$ was added to the film and hydration was carried out on ice with intermittent high-speed vortex mixing until all the lipid dispersed, and a homogeneous suspension was obtained. The suspension was extruded through the same series of polycarbonate membranes.

Neutral liposomes of DOPC:DOPE: Gc were combined at a 1:1:0.16 molar ratio, and the solution dried under nitrogen. The 500- $\mu \mathrm{L}$ aliquot containing the plasmid-PEI (1:4) complex was added to the film at RT and hydrated by alternate mild vortex mixing and warming at $37^{\circ} \mathrm{C}$ until complete lipid dispersion. The suspension was also extruded through the polycarbonate membrane series to $0.2 \mu \mathrm{m}$.

The lack of charge interaction with the anionic and neutral lipids together with the smaller particle size (4-7-nm diameter) of the 68-mer oligonucleotides allowed encapsulation without compaction with PEI. Therefore, $500 \mu \mathrm{L}$ of the fluorescently labeled oligonucleotides in $0.15 \mathrm{M} \mathrm{NaCl}$ were used to hydrate the lipid films and form the negative and neutral liposomes as described above.

\section{Analyses of Liposome Formulations}

Size analysis of the DNA-PEI complexes and liposomes was determined by light-scattering measurements on a NICOMP 370 Submicron Particle Size Analyzer (Pacific Scientific Instru- 
ments, Santa Barbara, CA, USA). Liposome aliquots of $20-50 \mu \mathrm{L}$ were diluted to $500 \mu \mathrm{L}$ using Milli-Q water, and the phospholipids were extracted twice using $500 \mu \mathrm{L}$ of chloroform: methanol (1:1 vol/vol). The organic phase was dried down under a stream of nitrogen. The lipids were redissolved in $2 \mathrm{~mL}$ of chloroform, and the final phospholipid concentration in the preparations was determined by the method of Stewart (22). Phospholipid concentration was determined from standard curves generated for each particular lipid mixture.

The DNA content of the liposomes was determined following DNA extraction and precipitation as follows: $40-50$ $\mu \mathrm{L}$ of liposome suspension were diluted with $300 \mu \mathrm{L}$ of heparin $(1 \mathrm{U} / \mu \mathrm{L})$ and incubated at $37^{\circ} \mathrm{C}$ for $3 \mathrm{~h}$. An equal volume of phenol:chloroform mixture was added and vortex mixed. The mixture was centrifuged at high speed for 2 min at RT, and the top aqueous phase was collected in a fresh tube. DNA was precipitated at $-20^{\circ} \mathrm{C}$ overnight following the addition of $80 \mu \mathrm{L}$ of $3 \mathrm{M}$ sodium acetate $(\mathrm{pH} 5.2), 500 \mu \mathrm{L}$ isopropanol, $10 \mu \mathrm{g}$ of tRNA and $300 \mu \mathrm{L}$ RNAmate $^{\circledR}$ (Intermountain Scientific, Kaysville, UT, USA). An aliquot of the PEI-DNA complex was subjected to the same extraction procedure and analyzed simultaneously with DNA extracted from the liposomes. The DNA was analyzed by $1 \%$ (plasmid) or $4 \%$ (oligonucleotide) agarose gel electrophoresis containing $1 \mu \mathrm{g} / \mathrm{mL}$ ethidium bromide and visualized using UV light. The relative intensities of the bands obtained were analyzed by densitometry using a Model GS-700 Imaging Densitometer (Bio-Rad, Hercules, CA, USA), and the amount of DNA in the liposome formulations was calculated based on the amount of DNA present in the complex.

\section{Cell Cultures}

HuH-7 human hepatoma cells were maintained in Dulbecco's modified Eagle medium (DMEM) (Life Technologies) containing $10 \%$ heat-inactivated fetal bovine serum (FBS) (Atlanta Biologicals, Norcross, GA, USA) and 1\% penicillin-streptomycin in tissue culture flasks at $37^{\circ} \mathrm{C}$ in a humidifed $5 \%$ $\mathrm{CO}_{2}$ atmosphere. Cells were grown to approximately $80 \%$ confluency, detached using trypsin-EDTA (Life Technologies) and replated at a density of 2 $\times 10^{5}$ cells/35-mm dish. The cultures were maintained in the same medium for $18-24 \mathrm{~h}$ before transfection. Primary rat hepatocytes were isolated from male Sprague-Dawley rats (175-250 g) (Harlan Sprague-Dawley, Indianapolis, IN, USA) using a two-step collagenase perfusion procedure described previously (15). The hepatocytes were plated at a concentration of $3 \times 10^{5}$ cells per $35 \times 10-\mathrm{mm}$ Primaria ${ }^{\mathrm{TM}}$ dishes (Becton Dickinson Labware, Bedford, MA, USA) and maintained for 18-24 h before transfection in William's E medium (Life Technologies) supplemented with L-glutamine, $0.01 \mathrm{U} / \mathrm{mL}$ insulin, $2 \mathrm{mM}$ HEPES, $23 \mathrm{mM} \mathrm{NaH}$ $\mathrm{CO}_{3}, 0.01 \mu \mathrm{M}$ dexamethasone and $10 \%$ heat-inactivated FBS. HeLa cells were plated at a density of $2 \times 10^{5}$ cells/35-mm dish $24 \mathrm{~h}$ before transfection and were maintained in Ham F-12 medium (Life Technologies) containing $10 \%$ heat-inactivated FBS.

\section{Transfections}

Positive and neutral liposomes were warmed to $37^{\circ} \mathrm{C}$ for $10 \mathrm{~min}$ and diluted with prewarmed HEPES-buffered saline (HBS), $\mathrm{pH} 7.4$, to a final concentration of 1-4 $\mu \mathrm{g}$ DNA (based on the initial amount of DNA added to lipids) per $100 \mu \mathrm{L}$. The diluted suspensions were warmed again at $37^{\circ} \mathrm{C}$ for $10 \mathrm{~min}$ just before addition to the cells. Negatively charged liposomes were vortex mixed and diluted using HBS at RT as described above. Non-encapsulated DNA-PEI complexes were used as positive controls and diluted as indicated above. At the time of transfection, the DMEM was removed from the culture dishes, and the HuH-7 cells were washed twice with OPTI-MEM ${ }^{\circledR}$ (Life Technologies) supplemented with an additional $2.5 \mathrm{mM} \mathrm{CaCl}_{2}$ and then covered with $1 \mathrm{~mL}$ of the same medium. A $100-\mu \mathrm{L}$ aliquot of transfecting solution was added to each 35-mm dish. After $18 \mathrm{~h}$ of transfection, an additional $2 \mathrm{~mL}$ of DMEM containing 20\% heat-inactivated FBS were added, and the cells maintained for an additional 6-30 h. Hepatocytes were washed twice in the supplemented William's E medium containing additional $\mathrm{Ca}^{2+}(2.5 \mathrm{mM})$.
Transfecting solutions were prepared as described for the $\mathrm{HuH}-7$ hepatoma cells, and $100 \mu \mathrm{L}$ were used for each dish. After $18 \mathrm{~h}$, an additional $1 \mathrm{~mL}$ of serum-containing medium was added to each dish. HeLa cells were washed twice in Ham F-12 medium before transfection and then covered with 1 $\mathrm{mL}$ of medium containing an additional $2.5 \mathrm{mM} \mathrm{CaCl}_{2}$. Anionic liposomes, in $100-$ or $150-\mu \mathrm{L}$ aliquots in HBS, containing fluorescent oligonucleotides at a final concentration of $4 \mu \mathrm{g} / 100 \mu \mathrm{L}$ were added to HeLa cells, and the cells were incubated for $24 \mathrm{~h}$.

\section{Determination of Transfection Efficiency}

After $48 \mathrm{~h}$ of transfection with the pRSV-CAT plasmid, HuH-7 cells were washed twice with ice-cold $0.1 \mathrm{M}$ phosphate-buffered saline (PBS) and harvested by scraping. Cells were centrifuged at $3000 \times g$ for $8 \mathrm{~min}$ and then resuspended in 150-300 $\mu \mathrm{L} 0.1 \mathrm{M}$ PBS containing $1 \mathrm{mM}$ phenylmethylsulfonyl floride (PMSF) and subjected to three freeze-thaw cycles followed by centrifugation at $15000 \times g$ at $4^{\circ} \mathrm{C}$ for $2 \mathrm{~min}$. The supernatant was collected and its protein concentration determined using the Bio-Rad protein assay reagent according to the manufacturer's specifications (Bio-Rad). Transfection efficiency was determined by assaying for CAT expression using an enzyme-linked immunoabsorbent assay (ELISA) kit (5 Prime $\rightarrow 3$ Prime, Boulder, CO, USA) according to the manufacturer's recommendations.

Hepatocytes were harvested after 48 h using $200 \mu \mathrm{L}$ reporter lysis buffer, and the luciferase activity was determined using the luciferase assay reagent (Promega) according to the manufacturer's protocol. Hepatocytes and HeLa cells transfected with the fluorescently labeled oligonucleotides were fixed $24 \mathrm{~h}$ post-transfection in PBS, pH 7.4, containing 4\% paraformaldehyde (wt/vol) for $10 \mathrm{~min}$ at RT. Following fixation, the cells were counterstained using a $5 \mu \mathrm{M}$ solution of DiI (Molecular Probes) in $0.32 \mathrm{M}$ sucrose for $10 \mathrm{~min}$ according to the manufacturer's recommendation. After washing with $0.32 \mathrm{M}$ sucrose and then PBS, pH 7.4, the cells were sealed under coverslips using SlowFade ${ }^{\mathrm{TM}}$ Antifade 
Mounting Medium (Molecular Probes) in PBS and examined using a MRC1000 Confocal Microscope (Bio-Rad). The collection series were made at 1 $\mu \mathrm{M}$ steps. Hepatocytes incubated with liposomal formulations containing ethidium monoazide-labeled CAT plasmid, were fixed in $4 \%$ paraformaldehyde $24 \mathrm{~h}$ post-transfection and sealed under coverslips using glycerol. Fluorescence was visualized with a Model BH2 Microscope (Olympus, Lake Success, NY, USA), and greater than 300 cells for each treatment were evaluated for transfection efficiency.

\section{Statistical Analysis}

Statistical analysis was performed using InStat Version 2.01 (GraphPad Software, San Diego, CA, USA) to calculate analysis of variance (ANOVA) and Bonferroni multiple comparisons to test probability $(P)$ values. For twocolumn comparisons, the unpaired twotailed Students $t$ test was used.

\section{RESULTS}

\section{Characterization of Liposomal Formulations}

Positive and negative liposomes

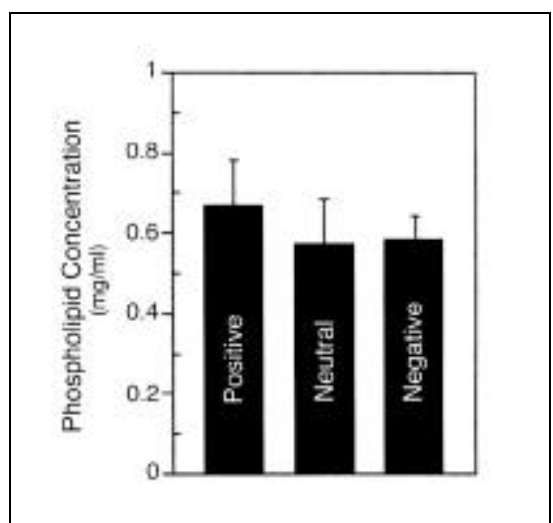

Figure 1. Final phospholipid concentration in liposomes following DNA encapsulation and extrusion. Positive (DOPC:DOTAP:Gc), neutral (DOPC:DOPE:Gc) and negative (DOPS:DOPC:Gc) liposomes were prepared by hydration of lipid films with aqueous soluble complexes of PEI and DNA or solutions of oligonucleotides as described under Materials and Methods. Following hydration liposomes were extruded through a series of polycarbonate membranes down to $0.2 \mu \mathrm{m}$. Phospholipids were extracted from liposomes and quantitated as described in Materials and Methods. The data represent the mean of 3 determinations \pm standard error of the mean (SEM). were formed as homogeneous suspensions following extrusion. Light-scattering measurements indicated an unimodal size distribution with an average number-weighted vesicle diameter between 100-150 nm (Table 1). The neutral liposomes, however, displayed a significantly larger mean diameter even after extrusion. The greater than 2-fold increase in size occurred only when hydration was carried out in the presence of PEI as compared to $0.15 \mathrm{M} \mathrm{NaCl}$ alone. The physical stability of the liposomes was also monitored by lightscattering measurements (Table 1). Formulations were stored for one month at $4^{\circ} \mathrm{C}$ or overnight at $37^{\circ} \mathrm{C}$. No significant changes in mean particle diameter were noted for the positively and negatively charged liposomes under either condition. However, the neutral liposomes were highly unstable and appeared to aggregate rapidly at $37^{\circ} \mathrm{C}$, leading to particles that were often greater than $2 \mu \mathrm{M}$ in diameter.

Following extrusion, a minimal loss of phospholipids was observed and the final phopsholipid concentration was very consistent for all three liposomal formulations (Figure 1). Analyses of the DNA content following extraction indicated that approximately $20 \%-30 \%$ of the initial plasmid-PEI complexes remained associated with the positive

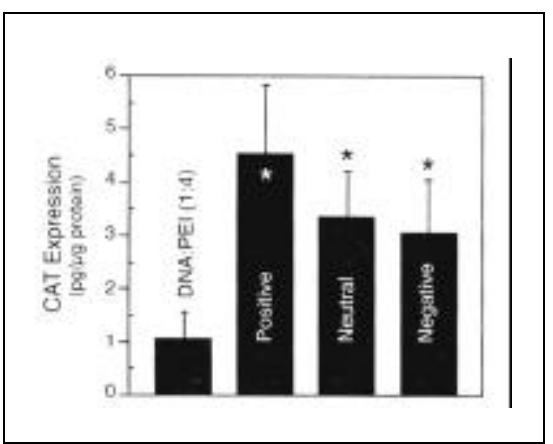

Figure 2. Transfection efficiency of PEI-condensed DNA with or without encapsulation in liposomes. The pRSV-CAT plasmid was complexed with PEI in a 1:4 ratio (DNA phosphate:PEI amine) for the positive and neutral liposomes and in a 1:2 ratio for the negative liposomes. The complexes were either added to HuH-7 cells directly or following liposomal encapsulation. Equivalent amounts of non-encapsulated PEI-DNA complexes and liposomes were added to the cells, which were harvested and assayed for CAT expression by ELISA after $48 \mathrm{~h}$. Values represent the mean of at least 10 determinations \pm SEM. $* P<0.001$ from 1:4 PEI control. 


\section{Gene Transfer Techniques}

and neutral liposomes. The amount of plasmid DNA (as a PEI complex) encapsulated in the negative liposomes was less. However, encapsulation efficiencies of greater than $40 \%$ were routinely obtained with the complexed/uncomplexed 68-mer oligonucleotides in all three liposomes.

\section{Transfection Efficiency of Liposomal Formulations}

The transfection efficiency of liposomes was found to be greater than that of the non-encapsulated DNA-PEI complexes. All liposomes (1-1.5 $\mu \mathrm{g}$ DNA per $2 \times 10^{5}$ cells) demonstrated a significant $(P<0.001)$ increase in CAT expression in the HuH-7 cells compared to the non-encapsulated DNAPEI complexes $(2-4 \mu \mathrm{g}$ DNA per $2 \times$ $10^{5}$ cells) (Figure 2). However, the transfection efficiency with the positively charged liposomes was signifi- cantly greater than that observed with the neutral $(P<0.05)$ or negatively charged liposomes $(P<0.01)$. No measurable CAT expression was observed with the non-encapsulated, PEI-plasmid complexes when the DNA dose was reduced to $1 \mu \mathrm{g}$ per $2 \times 10^{5}$ cells. In fact, a dose-dependent increase in CAT expression was observed when increasing amounts of the liposomal-DNA formulations were used to transfect the $\mathrm{HuH}-7$ cells; however, this was not the case of the non-encapsulated, PEI-plasmid complexes (Figure 3). Increasing the dosage of the PEI-DNA complex to $\mathrm{HuH}-7$ cells resulted primarily in increased cytotoxity and no significant change in CAT expression. Cell viability determined by trypan blue exclusion was $50 \%-60 \%$ of control for the nonencapsulated complexes after $48 \mathrm{~h}$ compared with $85 \%-95 \%$ for the encapsulated material. Moreover, the nonencapsulated PEI-DNA complexes that were stored for an extended period of time at $4^{\circ} \mathrm{C}$ exhibited highly variable transfection efficiency. In contrast, the positive liposomes showed no loss of transfection efficiency following storage at $4^{\circ} \mathrm{C}$ for 1 month (results not shown). The positive and negative liposomes were also significantly more efficient in transfecting the primary rat hepatocytes than the non-encapsulated, PEI-plasmid complexes (Figure 4). In fact, a greater than 100-fold increase in transfection efficiency was observed using the negatively charged liposomes (Figure 4B). Interestingly, the neutral liposomes did not appear as efficient in transfecting the hepatocytes as the positive and negative liposomes. However, for all three liposomal formulations, greater than $80 \%$ of hepatocytes were positive for ethidium monoazide-labeled CAT plasmid when the labeled DNA was transfected under identical conditions (results not shown). 


\section{Transfection of Fluorescently Labeled Oligonucleotides}

Cellular uptake of the fluorescein 3'end-labeled oligonucleotides was determined by confocal microscopy. The fluorescence uptake into the cells demonstrated that the negatively charged targeted liposomes were able to transfect primary rat hepatocytes more efficiently than either the positive or non-encapuslated, PEI-oligonucleotide complexes (Figure 5, A-C). Cytoplasmic labeling was present with both

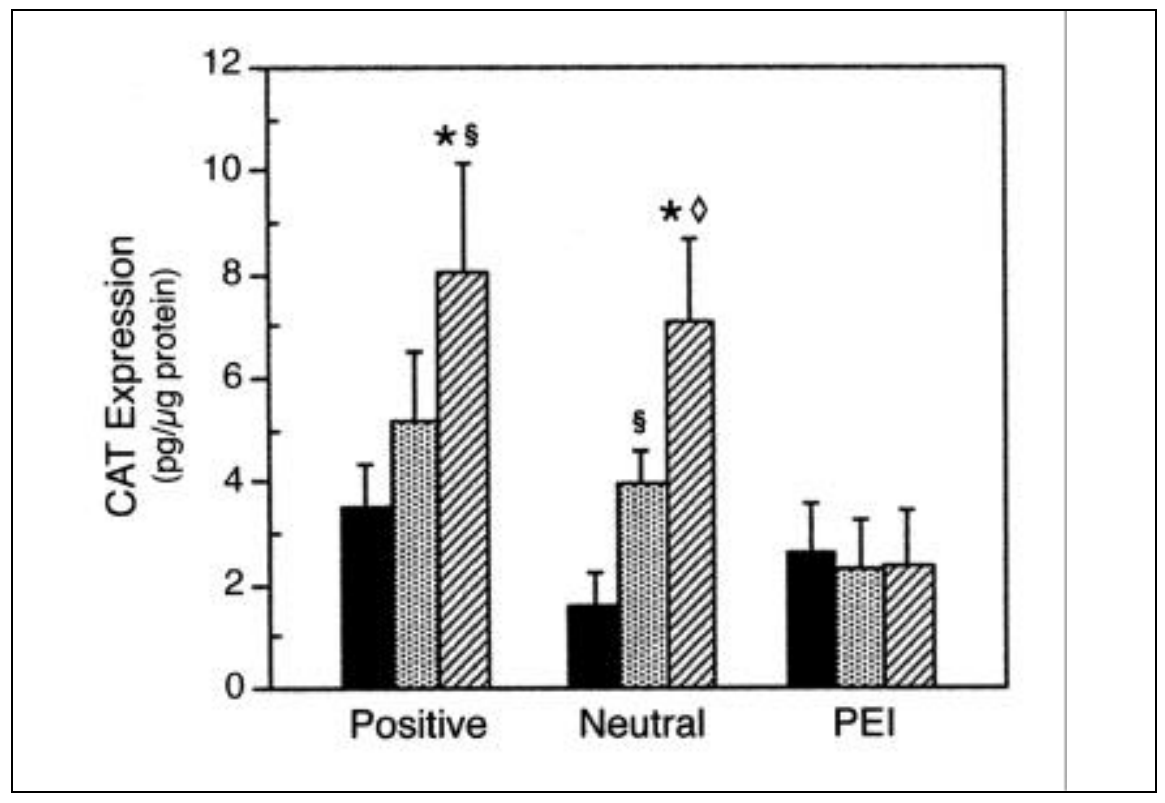

Figure 3. DNA dose-response of CAT expression in HuH-7 cells using liposome-encapsulated or non-encapsulated PEI-DNA complexes. Liposome-encapsulated, PEI-condensed pRSV-CAT plasmid concentrations were determined following DNA extraction and precipitation followed by detection in a $1 \%$ agarose gel as described in Materials and Methods. One (black), two (stipple) or four micrograms (bar) of DNA as encapsulated or non-encapsulated PEI-complexes were added to a fixed number of cells and the mean CAT expression measured after $48 \mathrm{~h}$. Values represent the mean of 4-6 determinations \pm SEM. $* P<0.001$ from $1 \mu \mathrm{g} ; \S P<0.05$ from 2 (positive) or $1 \mu \mathrm{g}$ (neutral); $\diamond P<0.01$ from $2 \mu \mathrm{g}$.
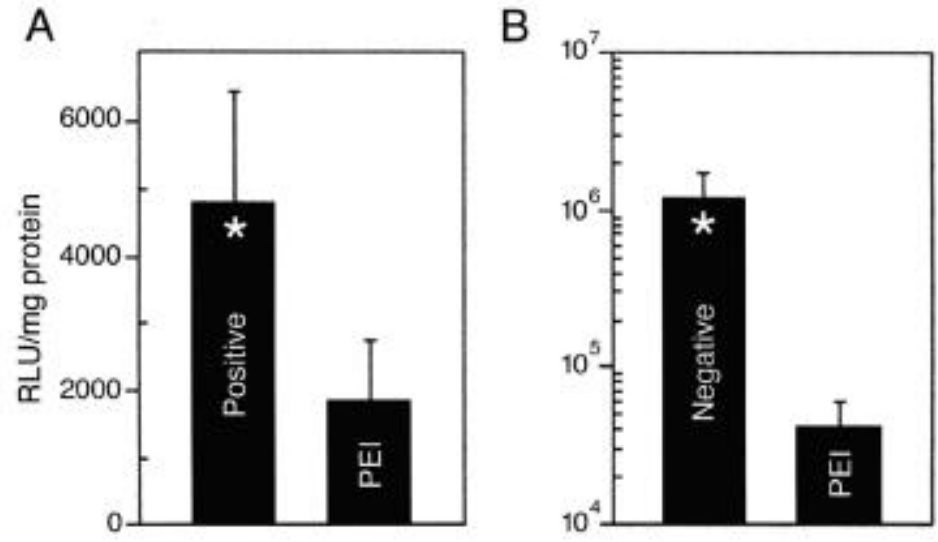

Figure 4. Transfection of primary rat hepatocytes with DNA-PEI complexes alone or encapsulated. Primary rat hepatocytes $\left(3 \times 10^{5}\right)$ were incubated with $1 \mu \mathrm{g}$ of PGL3 plasmid complexed to (A) PEI (1:4) or as a (1:4) DNA:PEI complex encapsulated in positive liposomes or (B) PEI (1:2) or as the $(1: 2)$ DNA:PEI complex encapsulated in negative liposomes. After $48 \mathrm{~h}$ of transfection, the hepatocytes were harvested, and luciferase activity was determined as outlined in Materials and Methods. Values shown are the means of 3-5 determinations \pm SEM. $* P<0.04$ from 1:4 PEI control; $P<0.03$ from 1:2 PEI control. 


\section{Gene Transfer Techniques}

the positive and negative liposomes, but a higher degree of nuclear labeling was observed with the negatively charged liposomes (Figure 5, B and C). The uptake of the anionic liposome-encapsulated, fluorescently labeled oligonucleotides was substantially decreased in the presence of $50 \mathrm{mM}$ D-galactose (Figure 5D). Confocal microscopy of hepatocytes incubated with negative liposome-encapsulated oligonucleotides that had been stored at $4^{\circ} \mathrm{C}$ for 1 month exhibited no detectable change in the uptake and cellular localization of the labeled molecule (results not shown). HeLa cells, which do not express the asialoglycoprotein receptor, were also transfected with the targeted anionic liposome-encapsulated fluorescent oligonucleotides. Even after prolonged in- cubation, no cytoplasmic and/or nuclear fluorescence was detectable (results not shown).

\section{DISCUSSION}

Three major considerations exist in the development of an optimal liposomal delivery system. These include: $(i)$ adequate encapsulation of therapeutic agents, (ii) physical and chemical stability of the formulation and (iii) optimal delivery to cells without significant cytotoxicity. Cationic liposome DNA complexes have been shown to be highly unstable, sensitive to serum and less efficient than systems in which the DNA is encapsulated $(3,8,13)$. We have described the preparation and charac- terization of three different liposomal gene delivery systems. The cationic lipid DOTAP was selected because of its low toxicity $(11,18)$ and better hepatocyte transfection properties as compared with other cationic lipids $(4,8$, 10,11). Phosphatidylserine was chosen as the anionic phospholipid instead of phosphatidic acid or phosphatidylglycerol because of its greater efficiency for gene delivery (5). Addition of PEI served to $(i)$ increase the percent liposomal encapsulation of the large DNA molecules by compacting the plasmid, and (ii) to possibly buffer lysosomal activity, thereby protecting the internalized DNA from degradation (2). Galactocerebroside or lactosylceramide has already been shown to be effective in targeting liposomes to hepatocytes in

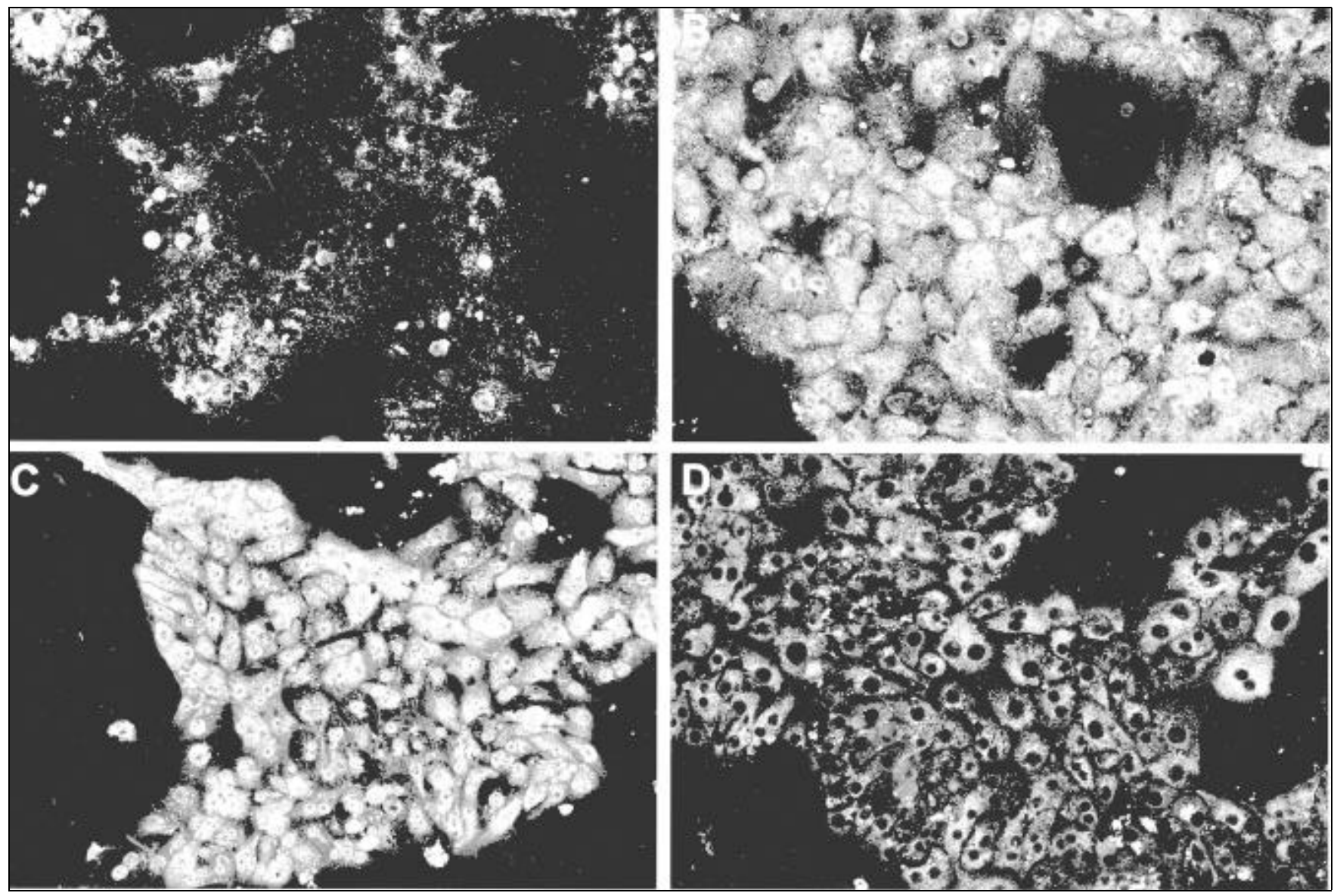

Figure 5. Confocal micrographs of primary rat hepatocytes transfected with fluorescently labeled oligonucleotides. Primary rat hepatocytes $\left(3 \times 10^{5}\right)$ were incubated with $4 \mu \mathrm{g}$ of fluorescein $3^{\prime}$-end-labeled, 68-mer oligonucleotides complexed to PEI or encapsulated in liposomes as detailed in Materials and Methods. After $24 \mathrm{~h}$ of transfection, the cells were fixed in $4 \%$ paraformaldehyde and counterstained with the cationic membrane probe DiI to visualize the cytoplasm. Double-label detection of the fluorescein (green) and DiI (orange) fluorescence was performed using a MRC-1000 Confocal Microscope. Hepatocytes were incubated with either non-encapsulated, PEI-oligonucleotide complexes (A); or encapsulated complexes in positive (B) and negative (C) liposomes as described in Materials and Methods. Co-incubation of negative liposome/encapsulated fluorescently labeled oligonucleotides and $50 \mathrm{mM}$ D-galactose resulted in a significant decrease in both cytoplasmic and nuclear fluorescence (D). 
vivo by way of their unique asialoglycoprotein receptors $(16,21)$. Addition of DNA to preformed cationic lipid/ DOPE liposomes often results in particles greater than $500 \mathrm{~nm}$, which are less efficient in gene transfer compared to liposome-encapsulated DNA $(3,13)$. Therefore, extrusion of liposomes following hydration with aqueous solutions of the PEI-DNA complexes or naked oligonucleotides was done to ensure greater stability and more reproducible transfections.

All three liposomal formulations exhibited at least a 2-fold higher transfection efficiency in HuH-7 cells than the non-encapsulated PEI-DNA complexes. However, in the primary rat hepatocytes, only the positively and negatively charged liposomes resulted in improved transfection efficiency. A DNA dosedependent transfection of HuH-7 cells was clearly observed using the liposomes, whereas no DNA dose-dependency was evident with the non-encapsulated, PEI-plasmid complexes. Moreover, increasing the amount of the non-encapsulated PEI-DNA complexes to the HuH-7 cells resulted in significantly higher cytotoxity. In addition to their increased cytotoxicity, PEI-mediated transfections were also associated with a greater degree of variability compared to the liposomal formulations.

Compared with positive and neutral liposomes, negative liposomes demonstrated a lower encapsulation efficiency with regard to the plasmid-PEI complex. This was presumably because of losses resulting from aggregation following the interaction between excess PEI and DOPS. However, despite the low encapsulation efficiency, negative liposomes were able to transfect cells at levels comparable with the other formulations. Taken together, these data suggested that the negatively charged liposomes might be, overall, a more efficient delivery system. We therefore, studied the uptake of fluorescently labeled oligonucleotides into cells after encapsulation in liposomes. Confocal microscopy revealed that the liposomes were far more efficient in delivering the fluorescently labeled oligonucleotides into both HuH-7 cells and primary rat hepatocytes than the non-encapsulated 1:4 oligonucleotide-PEI complexes. In both cell types, diffuse cytoplasmic as well as strong nuclear fluorescence was observed. This was in contrast to the lack of cellular fluorescence in transfected HeLa cells, which do not express the asialoglycoprotein receptor. Preincubation of the primary hepatocytes with $50 \mathrm{mM}$ D-galactose resulted in a significant decrease in the uptake of anionic liposomes, consistent with internalization by way of the galactose-specific asialoglycoprotein receptor.

Our results are in agreement with other studies in which anionic receptortargeted liposomal systems were more efficient for delivery of oligonucleotides to tumor cells (12). The liposomal systems described here were successful in intracellular delivery of functionally active DNA. For the plasmids, the presence of PEI probably played an important role in facilitating the release from the endosomes (2). Once released from the endosomal and/or lysosomal compartments, it has been proposed that oligonucleotides display an active "nuclear tropism" (25). The successful transfection of primary hepatocytes was conducted in the presence of $10 \%$ FBS, suggesting that the liposomal formulations may be as effective for in vivo delivery as well. In fact, biologically active recombinant DNA has been isolated from clathrincoated vesicles of rat livers following intravenous administration of DNA encapsulated in anionic-targeted liposomes (16).

Physical stability of the three different liposomal systems was determined by size analysis. Positive and negative liposomes showed no change in size distribution after storage for one month at $4^{\circ} \mathrm{C}$ or overnight at $37^{\circ} \mathrm{C}$. The neutral liposomes, however, exhibited aggregation both at $4^{\circ}$ and $37^{\circ} \mathrm{C}$. Incorporation of galactocerebroside slightly decreased the aggregation observed with the neutral liposomes, but it was still substantially greater than either the positive or negative liposomes. The physical characteristics of the neutral liposomes were better when naked, fluorescently labeled oligonucleotides were encapsulated compared to PEIcompacted particles, suggesting an interaction between the PEI and DOPC/ DOPE. It is possible that the stability of the neutral liposomal system might be enhanced by including cholesterol in 
the formulations. In addition to their physical stability, the cationic or anionic liposomes exhibited no detectable loss in transfection efficiency following storage for 30 days at $4^{\circ} \mathrm{C}$.

The positive and negative liposomal delivery systems described in this study can be well-characterized with regard to size, DNA and phospholipid content; thus, they are good candidates for development into a gene delivery system. The significant advantages conferred by this method of liposome preparation include $(i)$ size selection to substantially improve transfection efficiency in vivo (24); (ii) encapsulation of a known quantity of DNA in a smaller particle than that obtained by addition of nucleic acids to preformed liposomes (13, 24); (iii) long-term stability of the liposome-encapsulated DNA with no loss of transfection efficiency; (iv) reproducibility of transfection efficacy; $(v)$ decreased cytotoxicity of the encapsulated material; and (vi) efficient transfection of primary cells maintained in $10 \%$ FBS. These characteristics describe an overall more optimized formulation suitable for in vivo use. Finally, the efficient delivery, long-term stability, decreased cytotoxicity and reproducibility observed with these liposomal systems should dramatically reduce the variability of transfection experiments resulting from de novo preparation of transfecting material combined with instability of the delivery vehicle.

\section{ACKNOWLEDGEMENTS}

We thank Ms. Cheryle LinehanStieers for expert technical assistance, Drs. Bingrong Liu and Cary Mariash for assistance with primary hepatocyte isolations and Dr. Guangsheng Fan for helpful suggestions with fluorescence microscopy. This work was supported in part by a grant to C.J.S. from Kimeragen, Inc., Newtown, PA, USA.

\section{REFERENCES}

1.Bolton, P.H. and D.R. Kearns. 1978. Spectroscopic properties of ethidium monoazide: a fluorescent photoaffinity label for nucleic acids. Nucleic Acids Res. 5:4891-4903.

2.Boussif, O., F. Lezoualc'h, M.A. Zanta,
M.D. Mergny, D. Scherman, B. Demeneix and J.-P. Behr. 1995. A versatile vector for gene and oligonucleotide transfer into cells in culture and in vivo: polyethylenimine. Proc. Natl. Acad. Sci. USA 92:7297-7301.

3.Crespo, J., C. Blaya, A. Crespo and S.F. Aliño. 1996. Long-term expression of the human $\alpha 1$-antitrypsin gene in mice employing anionic and cationic liposome vectors. Biochem. Pharmacol. 51:1309-1314.

4.Fabrega, A.J., A.J. Fasbender, S. Struble and J. Zabner. 1996. Cationic lipid-mediated transfer of the hIL-10 gene prolongs survival of allogeneic hepatocytes in Nagase analbuminemic rats. Transplantation 62:1866-1871.

5.Fraley, R., R.M. Straubinger, G. Rule, E.L. Springer and D. Papahadjopoulos. 1981. Liposome-mediated delivery of deoxyribonucleic acid to cells: enhanced efficiency of delivery related to lipid composition and incubation conditions. Biochemistry 20:6978-6987.

6.Friend, D.S., D. Papahadjopoulos and R.J. Debs. 1996. Endocytosis and intracellular processing accompanying transfection mediated by cationic liposomes. Biochim. Biophys. Acta 1278:41-50.

7.Gao, X. and L. Huang. 1996. Potentiation of cationic liposome-mediated gene delivery by polycations. Biochemistry 35:1027-1036.

8.Ghoumari, A.M., O. Rixe, S.V. Yarovoi, A. Zerrouqi, R. Mouawad, T. Poynard, P. Opolon, D. Khayat and C. Soubrane. 1996. Gene transfer in hepatocarcinoma cell lines: in vitro optimization of a virus-free system. Gene Ther. 3:483-490.

9.Hofland, H.E.J., L. Shephard and S.M. Sullivan. 1996. Formation of stable cationic lipid/ DNA complexes for gene transfer. Proc. Natl. Acad. Sci. USA 93:7305-7309.

10.Holmen., S.L., M.W. Vanbrocklin, R.R. Eversole, S.R. Stapleton and L.C. Ginsberg. 1995. Efficient lipid-mediated transfection of DNA into primary rat hepatocytes. In Vitro Cell. Dev. Biol. 31:347-351.

11.Lappalainen, K., I. Jääskeläinen, K. Syrjänen, A. Urtti and S. Syrjänen. 1994. Comparison of cell proliferation and toxicity assays using two cationic liposomes. Pharm. Res. 11:1127-1131.

12.Lee, R.J. and L. Huang. 1996. Folate-targeted, anionic liposome-entrapped polylysinecondensed DNA for tumor cell-specific gene transfer. J. Biol. Chem. 271:8481-8487.

13.Legendre, J.-Y. and F.C. Szoka, Jr. 1992. Delivery of plasmid DNA into mammalian cell lines using $\mathrm{pH}$-sensitive liposomes: comparison with cationic liposomes. Pharm. Res. 9:1235-1242.

14.Litzinger, D.C. and L. Huang. 1992. Phosphatidylethanolamine liposomes: drug delivery, gene transfer and immunodiagnostic applications. Biochim. Biophys. Acta 1113:201-227.

15.Mariash, C.N., S. Seelig, H.L. Schwartz and J.H. Oppenheimer. 1986. Rapid synergistic interaction between thyroid hormone and carbohydrate on mRNA $_{\mathrm{S} 14}$ induction. J. Biol. Chem. 261:9583-9586.

16.Nandi, P.K., A. Legrand and C. Nicolau. 1986. Biologically active, recombinant DNA in clathrin-coated vesicles isolated from rat livers after in vivo injection of liposome-en- capsulated DNA. J. Biol. Chem. 261:1672216726.

17.Perales, J.C., G.A. Grossmann, M. Molas, G. Liu, T. Ferkol, J. Harpst, H. Oda and R.W. Hanson. 1997. Biochemical and functional characterization of DNA complexes capable of targeting genes to hepatocytes via the asialoglycoprotein receptor. J. Biol. Chem. 272:7398-7407.

18.Plank, C., K. Mechtler, F.C. Sczoka, Jr. and E. Wagner. 1996. Activation of the complement system by synthetic DNA complexes: a potential barrier for intravenous gene delivery. Hum. Gene Ther. 7:1437-1446.

19.Remy, J.-S., A. Kichler, V. Mordvinov, F. Schuber and J.-P. Behr. 1995. Targeted gene transfer into hepatoma cells with lipopolyamine-condensed DNA particles presenting galactose ligands: a stage toward artificial viruses. Proc. Natl. Acad. Sci. USA 92:17441748.

20.Smith, J.G., R.L. Walzem and J.B. German. 1993. Liposomes as agents of DNA transfer. Biochim. Biophys. Acta 1154:327340.

21.Spanjer, H.H. and G.L. Scherphof. 1983. Targeting of lactosylceramide-containing liposomes to hepatocytes in vivo. Biochim. Biophys. Acta 734:40-47.

22.Stewart, J.C.M. 1980. Colorimetric determination of phospholipids with ammonium ferrothiocyanate. Anal. Biochem. 104:10-14.

23.Strauss, M. 1994. Liver-directed gene therapy: prospects and problems. Gene Ther. 1:156-164.

24.Templeton, N.S., D.D. Lasic, P.M. Frederik, H.H. Strey, D.D. Roberts and G.N. Pavlakis. 1997. Improved DNA: liposome complexes for increased systemic delivery and gene expression. Nature Biotechnol. 15:647652.

25.Zabner, J., A.J. Fasbender, T. Moninger, K.A. Poellinger and M.J. Welsh. 1995. Cellular and molecular barriers to gene transfer by a cationic lipid. J. Biol. Chem. 270:1899719007.

26.Zhou, X. and L. Huang. 1994. DNA transfection mediated by cationic liposomes containing lipopolylysine: characterization and mechanism of action. Biochim. Biophys. Acta 1189:195-203.

Received 19 August 1997; accepted 19 January 1998.

Address correspondence to:

Dr. Clifford J. Steer

Department of Medicine

Box 36 UMHC

University of Minnesota

Medical School

420 Delaware Street S.E.

Minneapolis, MN 55455, USA

Internet: steer001@maroon.tc.umn.edu 